\title{
UK to set up advisory panel on genetic data
}

London. Britain seems likely to become the advisory committee to provide government ministers with advice on how they should regulate the use of genetic information.

This follows an announcement last week by Virginia Bottomley, the Secretary of Health, that such a committee — which would be non-statutory - may be set up after consultation with clinical geneticists, scientists, manufacturers of diagnostic tests and other products, and the public.

Various European countries bave already introduced legislation placing strict limits on the way in which genetic information can be first country in the world to set up a national

used. In several cases - as in US states such as California (see Nature 371,$468 ; 1994$ ) these have included a prohibition on the use of this information by insurance companies.

Bottomley's initiative appears to eschew this strategy by suggesting that an advisory committee "which would keep in touch with developments and act as a source of general advice to ministers" would be preferable to highly restrictive regulation.

Indeed, some observers say last week's announcement, whose tentative wording suggests that the idea is still in gestation in Whitehall, may be an attempt to forestall calls for even stricter measures in the report

\section{Curtain to fall on Beckenham lab}

London. Glaxo Wellcome, the world's largest pharmaceutical company following the $£ 9.4$ billion (US\$15.0 billion) takeover of Wellcome by Glaxo in March, has announced plans to close the former Wellcome UK research site at Beckenham, outside London, over the next three years.

The new company will concentrate all its British research at its recently opened £700-million Medicines Research Centre at Stevenage, north of London (see Nature 374, 756; 1995). Development work will take place mainly at Ware in Hertfordshire and Greenford in Middlesex.

The decision to close the Beckenham site will affect about 1,550 jobs, and brings down the curtain on one of Britain's most significant industrial research sites. The site, where the company's Wellcome Research Laboratories were originally opened in 1923, boasts five Nobel prizewinners, five Queen's awards for technological achievement, and a major role in the development of important drugs such as the AIDS treatment zidovudine.

But the closure was not wholly unexpected in the wake of Glaxo's sharply contested takeover of Wellcome. Indeed, the industry has expected jobs to disappear as the combined company pursues the cost-saving that Glaxo admits was one of the main motives behind its purchase of Wellcome.

Furthermore, last week's announcement may be only the tip of the iceberg. Market analysts believe that between 10,000 and 15,000 jobs could eventually go in the process of combining the two companies.

Glaxo Wellcome says the Beckenham closure is part of a strategy to increase efficiency and eliminate duplication in an industry that is changing at an unprecedented rate. "It is part of the process of creating a world-leading pharmaceutical company capable of competing in markets globally," says a company spokeswoman.
The precise number of jobs to be lost remains unclear. Of the 1,300 research and development staff at Beckenham, a significant number are expected to be retained by the new research and development organization. The decision to locate the whole of the new company's UK research at Stevenage has been based on the desire to get scientists working together in a state-of-the-art environment.

Stevenage has space to accommodate about 1,500 scientists, and is already home to 1,000 Glaxo researchers. Although no accurate breakdown is available, 500 of the Beckenham employees are believed to be engaged in research work, and 800 in product development.

At the end of the process, it is therefore likely that Stevenage will be at full capacity. Glaxo Wellcome remains coy about the likely number of redundancies, as the selection process for the new research and development organization, aimed at retaining what a spokeswoman describes as "the most appropriate people from the two former companies", has not yet been completed.

Employees are expected to know their fate by the end of September. The company is reluctant to speculate about how many may be asked to leave, arguing that it is concerned about the likely reaction of those asked to relocate.

But trade union officials fear the worst. Indeed, Paul Talbot, national pharmaceuticals officer for the union MSF (Manufacturing, Science, Finance), is already warning of likely resistance to compulsory redundancies, and is urging the company to give former Wellcome researchers sufficient time to weigh up relocation versus voluntary redundancy.

There is also considerable concern over the impact of closure on Beckenham. One estimate is that over $£ 100$ million will be lost from the local economy each year after Wellcome's researchers leave. Mike Ward of a House of Commons committee due to be published in the next few weeks.

The government's move was announced in a speech by Bottomley outlining what she considered to be the various successes of reforms to the National Health Service introduced over the past three years, and widely considered as her 'swan-song' before being moved to another department.

Acknowledging that developments in genetic testing will increasingly enable individuals to learn whether they are susceptible to certain diseases, Bottomley said it is clear that the government "has a public health and consumer protection role to ensure that such tests are supplied and used ethically".

She added that individuals need to be prepared for the results and, if they are abnormal, "properly advised on the implications" - a reference to widespread concern over the problems that could arise following genetic screening if it is not backed by procedures designed to supply such advice. Recognizing the privacy issues involved, she also said that such information "needs to be protected".

The government's plans, although still at a preliminary stage, have been welcomed by members of the Nuffield Council on Bioethics. This acts as Britain's national bioethics committee, and published a report on genetic screening in 1993 asking for such a committee to be set up. "Bottomley's suggestion is very much in line with what we recommended," David Shapiro, the executive secretary of the council, said last week.

The move has also been welcomed by those particularly concerned about the pressures that the availability of genetic information will inevitably place on insurance companies to take such information into account in setting life and health insurance premiums.

"Setting up this committee at this time would get very wide support from all quarters - including, I suspect, the insurance industry," says Peter Harper, chairman of the Royal College of Physicians' clinical genetics committee.

At the same time, however, there is likely to be intense debate over who should be represented on such a committee, and in what capacity. Alastair Kent, for example, the executive director of the Genetics Interest Group, a lobbying organization, says that those who sit on any new committee should be "mindful of the need to cover as wide a range of views as possible".

Specific proposals on how such a committee might operate are likely to come in the report on human genetics from the House of Commons Select Committee on Science and Technology, which, over the past year, has been studying a wide range of issues relating to the social implications of human genetics.

David Dickson 